\title{
Can Rationalist Abductivism Solve the Problem of Induction?
}

\author{
James R. Beebe (University at Buffalo) \\ Forthcoming in Pacific Philosophical Quarterly
}

Laurence BonJour (1998) has recently proposed an a priori solution to the problem of induction. According to BonJour, it is necessarily true that explanations involving ordinary inductive conclusions are the best explanations of inductive premises, and we can be justified in believing this fact a priori. He contends that no empiricist account of justification that rejects or denigrates the a priori has any hope of solving the problem of induction. Because BonJour's claims about the problem of induction play a central role in both his critique of empiricism and his defense of rationalism, it is important to know whether the rationalist solution he offers actually succeeds.

After providing a brief overview of BonJour's solution in section I, I carefully examine the probability claims that form the core of his account in sections II and III. I argue that on the most charitable interpretation of these claims, almost all of the published objections that have been raised against them are erroneous. In section IV I argue that the most serious challenge facing BonJour's account stems from the purported necessity of claims he makes about the relative frequencies of worlds within the total class of possible worlds. After reflecting on the potential circularity and circuitousness of BonJour's solution (section V), I conclude that he has failed to offer a viable solution to the problem of induction. 
I.

BonJour (1998, 188ff.) sets up his solution by considering the class of inductive inferences where the following conditions are known to obtain:

(1.1) $m / n$ of observed As are Bs.

(1.2) A large number of As have been observed.

(1.3) Property $A$ is logically independent of property $B$.

(1.4) Each of the following observational conditions has been varied to a substantial degree:

(a) The locations of observation;

(b) The times of observation;

(c) The identity of the observers; and

(d) Any further conditions of the cognitive environment justifiably believed to be relevant to an accurate determination of the frequency of As in the population of Bs.

(1.5) There is "no relevant background information available concerning either the incidence of $B s$ in the class of $A$ s or the connection, if any, between being $A$ and being B.” (BonJour 1998, 189)

(1.6) The "observed proportion of As that are Bs, rather than varying irregularly over the range of possible values, converges over time to the fraction $m / n$ and thereafter remains at least approximately constant as significant numbers of new observations come in.” (BonJour 1998, 207)

When (1.1) through (1.6) are all true, BonJour refers to (1.1) as a 'standard inductive premise.' The 'standard inductive conclusion' in such a case will be: 


\section{(1.7) $m / n$ As are Bs. ${ }^{1}$}

BonJour $(1998,189)$ characterizes the challenge posed by the problem of induction as follows:

Is there any sort of rationale that can be offered for thinking that conclusions reached in this way are likely to be true if the inductive premise is true-or even that the chance that such a conclusion is true is enhanced to any degree at all by the truth of such a premise? If we understand epistemic justification in the way discussed earlier in this book, that is, as justification that increases to some degree the likelihood that the justified belief is true and that is thus conducive to finding the truth, the issue is whether inductive reasoning confers any degree of epistemic justification, however small, on its conclusion.

BonJour's (1998, 207) response to this challenge is based on the idea that "an objective regularity of a sort that would make the conclusion of a standard inductive argument true provides the best explanation for the truth of the premise of such an argument.” Thus, in certain respects, BonJour's project is a continuation of Gilbert Harman’s (1965; 1967; 1968) earlier attempt to show that inductive inference is a species of inference to the best explanation.

BonJour's a priori justification of induction proceeds in two stages. The first stage attempts to establish that it is highly likely there exists a non-chance explanation for why (1.1) through (1.6) are all true. BonJour (1998, 207-208) writes,

From an intuitive standpoint, the overwhelmingly obvious question to ask is: what is the explanation for this situation? Why does the observed proportion continue to approximate $m / n$ rather than fluctuating widely as new observations are made? This is not a situation that would obtain for just any choice of $A$ and $B$, and some reason seems to be needed for its occurring in the case in question. Of course, it is logically possible that the results in question represent the operation of nothing more than mere random 
coincidence or chance, but it seems evident, and, as far as I can see, evident on a purely $a$ priori basis, that it is highly unlikely that only coincidence is at work, an unlikelihood that increases rapidly as the number of observations is made larger.

On the basis of these reflections BonJour $(1998,208)$ claims that the following thesis is justified a priori:

(I-1) In a situation in which a standard inductive premise obtains, it is highly likely that there is some explanation (other than mere coincidence or chance) for the convergence and constancy of the observed proportion (and the more likely, the larger the number of cases in question).

In the second stage of his solution, BonJour argues that the most likely non-chance explanation for the truth of (1.1) through (1.6) is what he calls a 'straight inductive explanation.' According to such an explanation:

the observed proportion [of As that are Bs] converges on $m / n$ and thereafter remains relatively constant because (i) it is an objective, lawful fact about the world, deriving presumably from underlying causal processes or mechanisms of some sort, that approximately $\mathrm{m} / \mathrm{n}$ of all As are Bs, and (ii) the observed cases represent an unbiased sample of As and thus accurately reflect this objective regularity. (BonJour 1998, 209)

BonJour $(1998,212)$ maintains that the following thesis regarding straight inductive explanations is justified a priori:

(I-2) So long as the possibility that observation itself affects the proportion of As that are $B$ s is excluded, the best explanation, that is, the most likely to be true, for the truth of a standard inductive premise is the straight inductive explanation, namely that the observed proportion $m / n$ accurately reflects (within a reasonable degree of 
approximation) a corresponding objective regularity in the world (and this likelihood increases as the number of observations and the variety of the collateral circumstances of observation increases).

According to BonJour, theses (I-1) and (I-2) are necessarily true. He believes that if we can be justified in believing (I-1) and (I-2), we can both be justified in believing standard inductive conclusions and have in our possession a solution to the traditional problem of induction.

II.

Where the pair variable ' $\langle S, N\rangle$ ' ranges over all ordered pairs whose first members are propositions expressed by standard inductive premises and whose second members are propositions stating that there exist non-chance explanations of the relevant premises, (I-1) can be represented as follows:

(P1) $\forall\langle S, N\rangle[P(N \mid S)$ is high $]$.

Letting ' $\langle S, E\rangle^{\text {' }}$ range over pairs of standard inductive premises and straight inductive explanations of those premises, (I-2) can be represented as:

(P2) $\forall\langle S, E\rangle[P(E \mid S)$ is high $]$.

Because BonJour $(1998,209)$ takes straight inductive explanations to entail standard inductive conclusions, (P2) entails:

(P3) $\forall\langle S, C\rangle[P(C \mid S)$ is high $]$,

where ' $\langle S, C\rangle$ ' ranges over pairs of standard inductive premises and their respective standard inductive conclusions.

It is important to note that (P1) does not claim there is likely to be some non-chance explanation for every observed proportion. There does not seem to be any reason why the fact 
that some proportion of As have been observed to be Bs, taken by itself, should cry out for a nonchance explanation. What seems to require such an explanation, BonJour claims, is the fact that the observed proportion of As that are $B$ s has converged on a certain value and has remained relatively constant as significant numbers of new observations come in, that a large number of $A s$ have been observed, that $A$ and $B$ are logically independent, and that relevant observational conditions have been varied to a substantial degree. Thus, it is essential that any adequate assessment of BonJour's project interpret his claims about 'standard inductive evidence' as including not only propositions like (1.1) but propositions like (1.2) through (1.6) as well. Similar considerations apply to (P2). Whatever likelihood straight inductive explanations possess is due to relations they bear to standard inductive evidence, not to any a priori likelihood they possess on their own.

Some of BonJour's critics seem to misunderstand what the relevant evidence base is for the conditional probability judgment made in (I-1) and (I-2). Hilary Kornblith (2000, 85, emphasis added), for example, writes:

Let us take a concrete example. All the crows I've seen have been black. Should I believe that all crows are black, and, if so, why? BonJour grants that it is not a priori likely that the world is orderly rather than chaotic. And of course it is not a priori likely that all crows are black relative to no evidence at all. But relative to the evidence that all crows I've seen have been black, BonJour says that it is a priori likely that all crows are black. Now why should this be so? In particular, given that it is no more likely a priori that I live in an ordered world than that I live in a world without order, why should my observation of a bunch of black crows give me any sort of reason, by itself, to think that all crows are black? BonJour's answer is that we are justified in believing this a priori. 
In asking why an observation of "a bunch of black crows" should give him any reason by itself to think that all crows are black, Kornblith seems to be taking standard inductive evidence to include only propositions like (1.1). This leads Kornblith (ibid.) to claim:

I don't know whether I am idiosyncratic here, but I don't find this suggestion any more plausible than the suggestion which BonJour agrees is implausible, that it is a priori likely that the world is orderly rather than chaotic. I recognize that this doesn't count as an argument, but I'm at a loss as to what else I should say on this score.

BonJour would agree that the observation of a bunch of crows "by itself" can only justify someone in believing that some observed crows are black. That observation cannot even justify one in believing a standard inductive premise, since this involves not only propositions such as (1.1) but propositions such as (1.2) through (1.6) as well. Furthermore, BonJour would agree that this observation alone cannot justify one in believing either that the standard inductive conclusion is true or that the standard inductive premise provides support for the standard inductive conclusion. Further justificatory resources are certainly needed, many of which will be provided by rational insight.

Other critics have expressed skepticism about the a priori reasoning process BonJour's solution allows us to go through when considering particular inductive inferences. Anthony Brueckner (2001, 5), for example, has raised the following concern. Letting 'Pr( )' stand for 'It is highly likely that( )' and 'A( )' for 'We know a priori that( ),' Brueckner glosses BonJour's theses (I-1) and (I-2) as:

(*) A[Pr(There is some correct explanation for the truth of a standard inductive premise)] and 
$(* *) \mathrm{A}[\operatorname{Pr}($ If $e$ is the correct explanation for the truth of a standard inductive premise, then $e$ is a straight inductive explanation)].

From $(*)$ and $(* *)$, Brueckner claims we can conclude:

$\left({ }^{* *}\right) \mathrm{A}[\operatorname{Pr}($ There is some correct, straight inductive explanation for the truth of a standard inductive premise)].

The problem, as Brueckner $(2001,5)$ sees it, is this:

But now it appears that we have something like a recipe for turning individual inductive inferences into deductions, contrary to BonJour's intention as described above. For any such inference, there will be an a priori argument involving *, ** and $* * *$ for the thesis that it is likely that the inductive inference's conclusion is true. This is not quite the same thing as turning induction into deduction, however, since the BonJour-style a priori argument does not yield the unvarnished thesis that the given inference's conclusion is true simpliciter.

Brueckner, however, misrepresents not only theses (I-1) and (I-2) but the nature of the justification BonJour claims we can have for standard inductive conclusions as well.

Brueckner interprets (I-1) as the claim that we can know a priori that it is highly likely there is some correct explanation for the truth of a standard inductive premise. Although BonJour claims that (I-1) can be known a priori, (I-1) does not itself make any claims about the epistemic status of any proposition. Thus, $\left({ }^{*}\right)$ should not include an epistemic operator. Even if Brueckner had left the 'A( )' off of $(*)$, it still would have failed to make clear the fact that (I-1) is making a claim about a certain conditional probability. Similar remarks apply to Brueckner's use of the epistemic operator ' $\mathrm{A}()^{\prime}$ ' in (**). Moreover, Brueckner represents (I-2) as a conditional claim falling within the scope of a probability operator (which, of course, falls within 
the scope of an epistemic operator). But (I-2) is primarily a claim about a certain conditional probability, and probabilities of conditionals have been shown to be nonequivalent to conditional probabilities. ${ }^{2}$ Even if it were appropriate to render (I-2) as a claim about the probability of a conditional, the obvious choice would have been:

(****) $P$ (If (1.1) through (1.6) are true, the observed proportion $m / n$ accurately reflects a corresponding objective regularity in the world) is high

rather than the one Brueckner provides. Whatever logical relation $(* *)$-with or without the ‘A( )’ operator-may bear to (I-2), it is not one of logical equivalence.

Furthermore, Brueckner’s worry that BonJour is “turning individual inductive inferences into deductions” is misplaced. BonJour does attempt to provide resources for constructing a certain kind of deductively valid argument concerning individual inductive inferences. But this sort of deductive argument appears harmless once it is properly understood. Let ' $S_{1}$ ' denote a particular standard inductive premise; ' $C_{1}$ ' the corresponding standard inductive conclusion; ' $N_{1}$ ' the claim that there is a non-chance explanation of $S_{1}$; and ' $E_{1}$ ' a straight inductive explanation of $S_{1}$. BonJour's solution allows us to construct the following valid argument about the inference from $S_{1}$ to $C_{1}$ :

(2.1) $P\left(N_{1} \mid S_{1}\right)$ is high.

(2.2) $P\left(E_{1} \mid S_{1}\right)$ is high.

(2.3) $\therefore, P\left(C_{1} \mid S_{1}\right)$ is high.

(2.1) and (2.2) follow from (P1) and (P2) by universal instantiation. (Interestingly enough, (2.3) follows from (2.2) alone because, on BonJour's account, a straight inductive explanation entails the relevant standard inductive conclusion. Thus, there appears to be no genuine need to suppose that (2.1) is true. BonJour, however, apparently thinks premises such as (2.1) are essential to the 
justification of inductive inferences.) The important thing to notice is that (2.3) is not a standard inductive conclusion. Rather, it is a conditional probability claim about the relation between a standard inductive premise and a standard inductive conclusion. So, the argument from (2.1) to (2.3) is not a case where an induction has been turned into a deduction.

Furthermore, there should not be anything worrisome about the fact that BonJour's account licenses a deductive argument for (2.3) because if (2.3) were added as a premise to a standard inductive argument, the latter would remain inductive and, therefore, invalid. Consider the following argument:

(3.1) $S_{1}$ is true.

(3.2) $P\left(N_{1} \mid S_{1}\right)$ is high.

(3.3) $P\left(E_{1} \mid S_{1}\right)$ is high.

(3.4) $E_{1}$ entails $C_{1}$

(3.5) $P\left(C_{1} \mid S_{1}\right)$ is high.

(3.6) $\therefore, C_{1}$ is true.

Statements (2.1), (2.2) and (2.3) appear in the present argument as premises (3.2), (3.3) and (3.5), respectively. (This formulation of the argument is somewhat infelicitous because (3.5) actually functions as something like an inductive inference rule rather than as a premise. If we insist upon representing all our inference rules as premises, we will be faced with the same problem that befuddled Lewis Carroll's (1895/1995) Achilles.) Note that the inference to (3.6), a standard inductive conclusion, is not deductively valid. (3.5) can be deductively inferred from (3.3) and (3.4), but the inference from (3.1) and (3.5) to (3.6) is at best inductively strong. Thus, although BonJour's solution gives us the resources to construct a deductive argument for (2.3), the deductive argument from (2.1) to (2.3) is not a standard inductive argument and the addition 
of (2.3) to a standard inductive argument does not turn the latter into a deduction. So, it is not the case that BonJour's a priori justification of induction attempts to turn inductions into deductions.

Brueckner is also worried about the apparent fact that "For any [standard inductive] inference, there will be an a priori argument involving *, ** and *** for the thesis that it is likely that the inductive inference's conclusion is true." Brueckner seems to misunderstand how BonJour thinks both a priori and a posteriori elements contribute to the justification of an inductive conclusion. BonJour maintains that our justification for premises (3.2) through (3.5) would be a priori, but our justification for (3.1) —an observational premise about contingent facts in the actual world—can only be a posteriori. As a result, our justification for believing (3.6) will have both a priori and a posteriori components. BonJour $(1998,2)$ follows the philosophical tradition in calling the total justification conferred upon such a conclusion $a$ posteriori. Thus, BonJour's account does not have the untoward consequence of allowing purely a priori knowledge of contingently true inductive conclusions.

\section{III.}

As we have seen, BonJour takes the central theses of his solution to the problem of induction to be necessarily true. Commenting on the modal status of (I-1), BonJour (1998, 208-209) writes:

Thus the relevant claim would be that it is true in all possible worlds that there is likely to be a non-chance explanation for the truth of a standard inductive premise. This would not mean, of course, that there could not be cases in a particular possible world in which such a non-chance explanation was in fact not to be found. It does not even mean that in a particular possible world, which might of course be the actual world, such cases in 
which there is no non-chance explanation for the truth of a standard inductive premise could not be substantially more numerous than those for which an explanation exists. But it would mean that such possible worlds involve the repeated recurrence of an unlikely situation—and hence that they are quite rare and unlikely within the total class of possible worlds. And this in turn would make the claim that the actual world is not such a world itself highly likely to be true, which is essentially what thesis (I-1) says.

Thus, although BonJour believes (I-1) to be necessarily true, he also subscribes to the following claims:

(P4) Counter-inductive worlds are possible. ${ }^{3}$

(P5) Standard inductive premises that are true at counter-inductive worlds make probable the existence of non-chance explanations of those premises—even though no nonchance explanations of those premises exist at counter-inductive worlds.

BonJour also seems to be clearly committed to the following claims as well:

(P6) Standard inductive premises that are true at counter-inductive worlds make probable straight inductive explanations of those premises - even though no straight inductive explanations of those premises are correct at counter-inductive worlds.

(P7) Standard inductive premises that are true at counter-inductive worlds make probable their respective standard inductive conclusions—even though standard inductive conclusions are rarely (if ever) true at counter-inductive worlds.

An important question to ask at this juncture is whether there is an interpretation of probability claims (P1) through (P7) that can make all of them true or at least coherent. Brueckner (2001, 6, notation altered) expresses the following doubts about there being such an interpretation: 
The special status of such alleged truths bears some reflection.... BonJour's view on these matters requires a conception of probability according to which the inductive premise makes the conclusion highly likely even in the counter-inductive worlds in which the corresponding conclusion is false. On such a conception, we cannot interpret $S$ makes $C$ highly likely as meaning that the conditional probability of $C$ given $S$ is high. That probability is zero, since

$$
P(C \mid S)=P(C \& S) / P(S)
$$

and

$$
P(C \& S)=0 .
$$

According to Brueckner, claims such as (P7) are not only false but obviously so. It is the obvious (apparent) falsity of (P7) and related claims that Brueckner finds puzzling and leads him to suggest that either (a) what BonJour means by ' $S$ makes $C$ highly likely' must be something other than 'the conditional probability of $C$ given $S$ is high' or (b) BonJour's position is ultimately incoherent.

The difficulty with Brueckner's interpretation is that he assumes that conditional probabilities can only be understood as relative frequencies of a certain kind. Consider the following reformulation of (P7):

(P7') ' $P(C \mid S)$ is high' is true at counter-inductive worlds.

On a frequentist view, ' $P(C \mid S)$ ' will be a measure of the proportion of $C$-worlds (i.e., worlds where ' $C$ ' is true) within the (perhaps restricted) set of $S$-worlds (i.e., worlds where ' $S$ ' is true). Brueckner assumes that set of $S$-worlds relevant for determining the value of the function ' $P(C \mid S)^{\prime}$ must be the set of counter-inductive $S$-worlds. However, this assumption is not mandated by the relative frequency interpretation of ' $P(C \mid S)$.' The relevant reference class (i.e., 
the relevant set of $S$-worlds) could very well be the entire set of $S$-worlds, which would include both counter-inductive and normal worlds. On such an interpretation, the value of ' $P(C \mid S)$ ' would be non-zero. If the relevant conditional probability were high, it would be high in all possible worlds, including counter-inductive worlds. Indeed, if the relevant reference class in (P7') were the entire set of S-worlds, the source of Brueckner's puzzlement would be removed. Consider the following, analogous cases:

(4.1) 'George W. Bush was elected President of the United States in the actual world' is true in all possible worlds.

(4.2) 'It is impossible for two plus two to equal five' is true in the actual world.

The fact that (4.1) mentions a statement that is true in all possible worlds does not mean that Bush needs to be elected President in every possible world in order for the statement as a whole to be true. The fact that (4.2) mentions a statement that is true in the actual world does not mean that the impossibility of two plus two equaling five should be determined only by what the sum of two and two is in the actual world. Similar considerations apply to (P7').

Accordingly, the most charitable interpretation of BonJour's probability claims seems to be one where probabilities concern frequencies across all possible worlds. Call such a view 'modal frequentism.'4 Because modal frequentism entails that probabilities remain the same across all possible worlds, it can make sense of BonJour's claim that (I-1), (I-2) and (P1) through (P7) are all necessarily true. Since modal frequentist claims express relationships between infinitely large sets of worlds, the relevant frequencies cannot be determined by simple ratios of the worlds picked out by attribute and reference classes. Modal frequentists must therefore appeal to the notion of limiting frequency. Consider an infinitely long (perhaps randomly selected) sequence of $S_{\mathrm{i}}$-worlds. Where ' $n$ ' denotes the $n$th place in this sequence and ' $m$ ' the 
number of $C_{\mathrm{i}}$-worlds in a given segment of the sequence, $P\left(C_{\mathrm{i}} \mid S_{\mathrm{i}}\right)$ will be the limit toward which the value of $m / n$ converges as $n$ increases toward infinity. (Of course, if there is no limit toward which $m / n$ converges, the value of $P\left(C_{\mathrm{i}} \mid S_{\mathrm{i}}\right)$ will be undefined.) Thus, according to the modal frequentist interpretation, (P1) is equivalent to the following claim about every standard inductive premise: within the set of worlds where a standard inductive premise is true, the limiting frequency of worlds where there exists a non-chance explanation of that premise is high. (P2) and (P3) make similar claims about straight inductive explanations and standard inductive conclusions. (P4) can be understood as the claim that the limiting frequency of counterinductive worlds within the total class of worlds is greater than 0 .

\section{IV.}

In a footnote to his remarks about the relative rarity of counter-inductive worlds, BonJour (1998, 209, n. 24) writes:

This way of putting the matter assumes in effect that it is possible to make sense of the relative size of classes of possible worlds, even though both those classes and the total set of possible worlds are presumably infinite. But I have no space to go into the issues surrounding this assumption and must be content here with saying that its intuitive credentials in other cases (e.g., the claim that there are twice as many positive integers as even integers) seem to me strong enough to make it reasonable to construe the difficulties as problems to be solved and not as insuperable objections.

These comments not only confirm that BonJour's central theses should be understood from the perspective of modal frequentism; they also point to the most serious challenge for any such approach. Limiting frequencies within infinite classes can only be defined relative to sequences 
(i.e., ordered sets) of worlds. When the reference and attribute classes are finite, the order (or lack thereof) is irrelevant because relative frequencies within finite sets can be determined by simple ratios of the cardinalities of the sets. When dealing with infinite sets, however, order becomes crucial. For example, although it is plausible to think that the relative frequency of the positive even integers within the set of all positive integers is $1 / 2$, it is only when the positive integers are taken in a particular order that this is the case. If, for example, the integers are ordered so that even numbers appear in every fourth place (i.e., 1, 3, 5, 2, 7, 9, 11, 4, 13, 15, 17, $6, \ldots$ ), their relative frequency converges to $1 / 4$ rather than $1 / 2$. In fact, by suitably reordering the integers, we can make the limiting frequency of evens converge to any value between 0 and 1 . The "intuitive credentials" of thinking the frequency of evens is $1 / 2$ seems to stem from the fact that there is a conventional or privileged ordering of integers, relative to which this is true.

The critical question for BonJour is which sequences of worlds are the basis for his claims about the limiting frequencies of counter-inductive worlds within the total set of possible worlds and about the limiting frequencies of worlds where standard inductive conclusions are true within the set of worlds where their standard inductive premises are true. The crucial difficulty is that there is no privileged or natural ordering of worlds to which BonJour can appeal. Yet if his claims about limiting frequencies are not relativized to any particular sequence(s) of worlds, the frequencies in question will be undefined and hence BonJour's claims about them cannot be true. ${ }^{5}$ Unfortunately, as his remarks in the previous quotation make clear, BonJour does not take any steps toward resolving this difficulty.

In the absence of a privileged ordering of worlds, it seems the modal frequentist's best bet is to make an appeal to randomness, where (P1) through (P7) are understood as claims about limiting frequencies within random sequences of worlds. ${ }^{6}$ For example, (P3) could be viewed as 
the claim that, for every $\langle S, C\rangle$, the limiting frequency of $C$-worlds within every random sequence of $S$-worlds is high. The analogous claim about even numbers would be that the limiting frequency of evens in every random sequence of positive integers would be $1 / 2$. The randomness requirement is intended to limit the set of admissible sequences so that sequences gerrymandered to achieve any desired result are excluded.

A variety of highly technical definitions of randomness have been proposed during the last half-century. However, because BonJour's claims about frequencies are something ordinary subjects are supposed to be able to apprehend without the need of advanced mathematical training, many of these definitions will not suit his purposes. Remaining on an intuitive level, then, it seems that a sequence will be random when there is no discernible pattern or regularity in the arrangement of its members and when knowing the value of the first $n$ items in the sequence provides no basis for predicting the value of the $n+1^{\text {st }}$ item. ${ }^{7}$ Given this understanding of randomness, an immediate question that arises for BonJour's probability claims (understood as claims about limiting frequencies in infinite random sequences) is why anyone should believe they are true. Why should we think the limiting frequency of $C$-worlds within every random sequence of $S$-worlds is high? And why should the limiting frequency of counter-inductive worlds in every random sequence of worlds be less than the limiting frequency of normal worlds?

The following thought experiment may provide some intuitive support for the claim BonJour makes about even numbers above. Perhaps it can then be modified to support BonJour's modal frequentist claims about normal and counter-inductive worlds.

Cosmic Lottery I Imagine a cosmic lottery machine that contains an infinite number of lottery balls. (Even though such a lottery machine is physically impossible, we 
can imagine such a device being simulated in the mind of God.) On each ball is inscribed one positive integer, and for every positive integer there is a ball with that number on it. The machine selects an infinitely long random sequence of balls. $^{8}$ The limiting frequency of even numbers within the sequence, as the number of drawn balls approaches infinity, is computed.

Would the limiting frequency of evens within such a sequence be $1 \frac{1}{2}$ ? There seems to be some intuitive pull toward answering "Yes," although this intuition does not seem to be universally shared. Consider also the following question: Would the limiting frequency of even numbers be greater than the limiting frequency of prime numbers in such an infinite random sequence? There seems (to me, at any rate) to be a stronger intuitive pull toward answering "Yes" to this second question than there is toward answering "Yes" to the previous one. (Potential problems with these would-be intuitions will be addressed below.)

Now consider a possible worlds variant of the cosmic lottery case:

Cosmic Lottery II Imagine a cosmic lottery machine that contains an infinite number of lottery balls. On each ball is inscribed an expression referring to a particular possible world, and for each possible world there is a ball containing an expression that refers to it. (Never mind what sorts of expressions these might be. Since we can again imagine the set-up being simulated in the mind of God, it seems an omniscient being should be able to refer to any particular possible world.) The machine selects an infinitely long random sequence of balls. The limiting frequency of normal worlds within the sequence, as the number of drawn balls approaches infinity, is compared to the limiting frequency of counterinductive worlds. 
Would the limiting frequency of normal worlds be greater than the limiting frequency of counterinductive worlds? I have to confess that I see no reason why it should be. Suppose another lottery machine contains only those balls that refer to worlds at which a particular standard inductive premise is true. As the number of drawn balls increases toward infinity, would the limiting frequency of worlds where the corresponding standard inductive conclusion is also true be greater than the limiting frequency of worlds where the conclusion is not true? Once again, I feel no intuitive pull toward answering "Yes" to this question. In contrast to the cosmic lottery case involving numbers, I have no intuitions at all about the relevant frequencies of these worlds.

Critics of course will allege that whatever intuitions we do have in the even number case will be illicitly based upon our habit of taking the integers in their conventional order. Our intuitions are supposed to be independent of our knowledge about integers in their conventional ordering, yet it seems that this knowledge is the very thing that gives rise to them. Indeed, without our knowledge that evens are more frequent than primes within this ordering, it is not clear that we would have any intuitions at all about the matter. And in fact this is exactly what we find in the case involving worlds. Because there is no conventional or privileged ordering of possible worlds, we find ourselves bereft of intuitions about the frequencies of normal and counter-inductive worlds. (A further complicating factor to consider is that the number of balls in Cosmic Lottery I is countably infinite, while the number of balls in Cosmic Lottery II is uncountable.)

The essential difficulty for BonJour's solution to the problem of induction is that it must be possible for us to apprehend a priori facts about the comparative frequencies of certain kinds of worlds (and perhaps also to apprehend them fairly easily). And yet it is far from clear how this could be possible. Not only has BonJour failed to provide us with an account of what it 
would mean for one sort of world to be more frequent in the total set of possible worlds than another, he has also given no clues about how we could recognize such facts if they were to obtain. If BonJour wants to remain committed to the claim that counter-inductive worlds are less frequent within the total class of possible worlds than normal worlds and that worlds where standard inductive conclusions are true are quite frequent within the set of worlds where standard inductive premises are true, he must find a way to deal with the profound semantic, metaphysical and epistemological difficulties facing such a proposal. ${ }^{9}$ Because he has not done so, he cannot be said to have solved the problem of induction.

V.

I conclude my discussion of BonJour's rationalist abductivism with two final considerations. Although there are many conceptions of what the problem of induction is and what a solution to it must provide, BonJour $(1998,189)$ characterizes the problem of induction as the challenge of finding an answer to the following question:

Is there any sort of rationale that can be offered for thinking that conclusions reached in this way are likely to be true if the inductive premise is true- or even that the chance that such a conclusion is true is enhanced to any degree at all by the truth of such a premise?

In other words, solving the problem of induction would mean showing the following to be true: (P3) $\forall\langle S, C\rangle[P(C \mid S)$ is high $]$.

BonJour's reason for thinking (P3) is true is that we can see $a$ priori that straight inductive explanations are more likely to be true than their competitors and that straight inductive explanations entail standard inductive conclusions. Recall that the relation of a priori likelihood 
that purportedly obtains between standard inductive premises and straight inductive explanations was represented as:

(P2) $\forall\langle S, E\rangle[P(E \mid S)$ is high].

Thus, the reason BonJour offers for believing (P3) is true is that we can see a priori that (P2) is true and that (P2) entails (P3).

However, the probabilification relation BonJour believes to obtain between inductive premises and straight inductive explanations in (P2) is the very same sort of relation that purportedly obtains between inductive premises and inductive conclusions in (P3). If the problem of induction stems from our apparent inability to provide non-circular reasons for thinking the latter relation obtains, that problem will not be resolved by any "rationale" that appeals to the obtaining of that same relation. Yet that is just what BonJour's proposal attempts to do. It seems, however, that an adequate solution to the problem of induction should provide independent reasons for believing the latter sort of relation obtains. ${ }^{10}$

Moreover, because BonJour believes the relevant probability relations that obtain between inductive premises and conclusions can be apprehended a priori, one wonders why he doesn’t simply skip all talk of “the best explanation” and jump straight to the following claim:

(P8) We can know that inductive premises support inductive conclusions because we can grasp a priori the necessary truth that the former probabilify the latter.

Since the truth of (P3), which is entailed by (P8), can be grasped in the same a priori way as the truth of (P2), it is not clear how much the discussion of (P2) and the explanatory superiority of straight inductive explanations really adds to BonJour's proposal. Of course, offering (P8) as his solution to the problem of induction would make solving the problem of induction seem so easy that few would believe the problem had actually been solved. If we can simply "see" that 
inductive premises make inductive conclusions likely, it will be completely mysterious why philosophers for centuries have thought the problem of induction presented us with a serious and perhaps unanswerable challenge. While (P8) does not represent BonJour's official solution to the problem of induction, it certainly seems to be entailed by that solution. Moreover, it seems that the other considerations BonJour offers are unnecessary, given his ultimate views about $a$ priori probabilities. Thus, it appears that BonJour needs to explain how some of the greatest minds in philosophy could be duped into thinking inductive skepticism posed a serious threat when in fact it can be avoided quite easily.

VI.

BonJour's a priori justification of induction is an intriguing attempt to solve one of the most intractable problems in the history of epistemology. Although it does not suffer from many of the flaws that critics allege it does, BonJour's appeals to limiting frequencies within infinite sets of worlds remain deeply problematic and the prospects for overcoming these difficulties do not seem to be bright. Thus, it seems the venerable problem of induction has resisted yet another attempt at resolving it. ${ }^{11}$

\section{References}

BonJour, Laurence. 1998. In Defense of Pure Reason. Cambridge: Cambridge University Press. Brueckner, Anthony. 2001. "BonJour's A Priori Justification of Induction." Pacific Philosophical Quarterly 82:1-10. 
Carroll, Lewis. 1895/1995. "What the Tortoise Said to Achilles.” Mind 104:691-693.

Fumerton, Richard. 1980. "Induction and Reasoning to the Best Explanation.” Philosophy of Science 47:589-600.

Harman, Gilbert. 1965. “The Inference to the Best Explanation.” Philosophical Review 74:88-95. . 1967. “Detachment, Probability, and Maximum Likelihood.” Noûs 1:401-411. . 1968. “Knowledge, Inference, and Explanation.” American Philosophical Quarterly 5:164-173.

Kolmogorov, Andrei N. 1965. "Three Approaches to the Quantitative Definition of Information.” Problems of Information Transmission. 1:4-7.

Kornblith, Hilary. 2000. “The Impurity of Reason.” Pacific Philosophical Quarterly 81:67-89.

Lewis, David. 1976. "Probabilities of Conditionals and Conditional Probabilities.” Philosophical Review 85:297-315.

Reichenbach, Hans. 1949. The Theory of Probability: An Inquiry into the Logical and Mathematical Foundations of the Calculus of Probability. Berkeley: University of California Press.

Von Mises, Richard. 1957. Probability, Statistics and Truth, $2^{\text {nd }}$ English edn. New York: Macmillan.

Wrenn, Chase B. 2006. "Inter-World Probability and the Problem of Induction." Pacific Philosophical Quarterly 87:387-402.

\footnotetext{
${ }^{1}$ Instead of treating claims (1.2) through (1.6) as premises in a standard inductive argument, BonJour treats them as background conditions that need to be satisfied in order for (1.1) to count as a standard inductive premise.
} 
As a result, the inductive arguments BonJour focuses on typically have only one premise and one conclusion. In what follows I will treat (1.2) through (1.6) as premises because our knowledge of them, on BonJour's account, is part of what justifies us in believing a standard inductive conclusion.

${ }^{2}$ Cf. Lewis (1976) for the technical details of such a proof.

${ }^{3}$ BonJour (1998, 204-205) also makes the following claims:

An a priori justification of induction need not involve the claim, which so many have rightly found implausible, that the principle of induction (as roughly formulated in §7.1) or some similar principle concerning the uniformity of nature is a self-evident, a priori truth. Such a claim seems obviously untenable. It would mean, as has again been widely pointed out, that a chaotic universe could somehow be ruled out as even an a priori possibility; whereas it seems clear on an intuitive basis that this is not so, that such a universe is a priori quite possible.

${ }^{4}$ Reichenbach's $(1949, \S \S 73,80)$ attempt to extend the frequency interpretation to cover both the probabilities of statements and the modalities constitutes an early form of modal frequentism.

${ }^{5}$ Cf. Wrenn (2006) for a series of well-aimed attacks on BonJour's claims about the relative frequencies of normal and counter-inductive worlds using what Reichenbach (1949, §40) calls a 'geometric interpretation' of frequentist probability.

${ }^{6}$ Some frequentists—e.g., von Mises (1957)—have denied that the notion of probability has any application to sequences that are not random. Other frequentists—e.g., Reichenbach (1949, 132, 151)—have not required sequences to satisfy a randomness constraint in order for their frequency theories to be applied.

${ }^{7}$ In addition to seeming to do a fair job of capturing the central threads of the intuitive notion of randomness, the current definition also seems to comport well with the spirit of some of the most prominent technical accounts of randomness, including Kolmogorov's (1965) definition of a random sequence as one where the shortest program that can generate it is no shorter than the one that simply lists the elements of the sequence one by one and equivalent definitions in terms of informational incompressibility. It also seems to square well with von Mises' (1957) informal explication of his notion of randomness in terms of the impossibility of a successful gambling system (i.e., an illusory scheme to make one's chances at gambling greater than those predicted by a mathematical calculation of the odds). 
${ }^{8}$ The relevant notion of randomness should be understood to apply to sequences themselves rather than to the processes that generate those sequences. The reason for this qualification is that it is possible for a random process to generate (by chance) a highly ordered and hence non-random sequence.

${ }^{9}$ A further difficulty with BonJour's claims about the relative rarity of counter-inductive worlds is that these claims seem to run afoul of plausible restrictions on what an a priori solution to the problem of induction can deliver. On the one hand, BonJour (1998, 213) writes:

Reichenbach insists, correctly, that the thesis that the world is completely chaotic is neither impossible nor even unlikely from a strictly a priori standpoint, and I have said nothing to dispute this claim.

Thus, BonJour claims it is not a priori unlikely that the world should be chaotic. Yet he insists it is a priori unlikely that the world is counter-inductive. If the first claim is true, it is not clear how the second one can be true. Part of the worry with the second sort of claim stems from the intuition that there cannot be a wholly a priori solution to the problem of induction. Throughout most of his account, BonJour writes as if a priori and a posteriori justificatory components combine to justify standard inductive conclusions. For example, he maintains that if we are a posteriori justified in believing a standard inductive premise, we can be a priori justified in believing that the standard inductive premise makes probable the relevant standard inductive conclusion. The justification of the conclusion will thus have both a priori and a posteriori components. However, if we can know that counter-inductive worlds are a priori unlikely, it is not clear that we need any a posteriori justificatory element at all to solve the problem of induction. If we can simply see by the power of rational insight the relative rarity of counter-inductive worlds, then the appropriate response to the challenge of inductive skepticism is that we can simply see that it is false. This, of course, does not represent BonJour's strategy and indeed seems inconsistent with the overall tenor of his approach. Yet it seems to be allowed by some of his remarks.

${ }^{10}$ Harman $(1965 ; 1967 ; 1968)$ has argued that inductive inferences are actually inferences to the best explanations and, therefore, that the distinction between induction and abduction collapses. Fumerton (1980) maintains the distinction collapses in the other direction, with all apparently abductive inferences being either straightforwardly inductive inferences or inferences that combine inductive and deductive elements. While BonJour's project seems continuous with Harman’s to some extent, it is not clear whether BonJour wants to collapse this distinction altogether. If BonJour were to deny the existence of a separate category of abductive inference, his response to the problem of induction would be circular by virtue of appealing to one form of inference to justify that 
very same form of inference. Yet even if BonJour were to preserve the distinction between inductive and abductive inference, his account would be circular because his account of seeing what the best explanation is appeals to the same a priori grasping of logical probabilities that he thinks is involved in seeing that an inductive premise supports an inductive conclusion.

${ }^{11}$ I would like to thank John Kearns, Nick Shackel, Lisa Warenski, Roger White and audiences at the 2005 Meeting of the Creighton Club and the 2006 Pacific Division Meeting of the APA for helpful comments and feedback on previous drafts of this essay. 